\title{
Sujeto y política: vínculos y modos de subjetivación
}

\begin{tabular}{l|l} 
Investigaciones & $\begin{array}{l}\text { Revista Colombiana } \\
\text { de Educación, N. 63. } \\
\text { Segundo semestre de 2012, } \\
\text { Bogotá, Colombia. }\end{array}$
\end{tabular}

\section{//Subject and politics: Subjectivity}

links and types

//Sujeito e política: vínculos e modos de subjetivação

\section{María Cristina Martínez Pineda* Juliana Cubides**}

Recibido:16/08/2012 Evaluado:30/08/2012

\begin{abstract}
Profesora investigadora de la Universidad Pedagógica Nacional, integrante del grupo Educación y Cultura Política. Magíster en Educación, Doctora en Filosofía y Ciencias de la Educación. Correo electrónico: mmartiez@pedagogica.edu.co

Politóloga y Magíster en Sociología de la Universidad Nacional de Colombia. Investigadora del Grupo de Trabajo de CLACSO Juventud y Prácticas Políticas en América Latina. Coordinadora General del Observatorio de Juventud de la Universidad Nacional de Colombia. Estudiante de Doctorado en Estudios Latinoamericanos de la Unam. México. Correo electrónico: juliana.cubides@gmail.com
\end{abstract}

\section{Resumen}

El presente artículo se fundamenta en las investigaciones coordinadas por las autoras y se orienta a desentrañar los vínculos entre sujeto y política con el interés de precisar acercamientos metodológicos que coadyuven, desde la investigación, a la constitución de subjetividades políticas contemporáneas. Para su desarrollo, el texto se estructura en tres apartados: palabras previas, acercamientos a la categoría de subjetividad política en procesos investigativos y pistas para su configuración.

\section{Abstract}

This paper is based on a research organized by authors and focused to unravel links between subject and politics in order to clarify methodological approaches that contribute from research to develop contemporary political subjectivities. Text is divided into three sections: i) introduction; ii) approaches to category of political subjectivity in research processes; and iii) hints for a pattern.

\section{Resumo}

O presente artigo se fundamenta nas investigações coordenadas pelas autoras e se orienta para desentranhar os vínculos entre sujeito e política com o interesse de precisar aproximações metodológicas que coadjuvem, a partir da investigação, à constituição de subjetividades políticas contemporâneas. Para seu desenvolvimento, o texto se estrutura em três partes: i) palavras prévias, ii) aproximações à categoria de subjetividade política em processos investigativos e iii) pistas para sua configuração.

\section{Palabras Clave}

Sujeto político, subjetividad política, la política, acciones colectivas, instituido-instituyente, constitución de subjetividades.

\section{Keywords}

Political subject, political subjectivity, politics, collective action, constituted-constituent, subjectivity formation.

\section{Palavras chave}

Sujeito político, subjetividade política, a política, ações coletivas, instituído-instituinte, constituição de subjetividades. 


\section{Palabras previas}

La pregunta por el vínculo entre sujeto y política y desde este por la constitución de subjetividades políticas alternativas o emergentes ha sido un punto de partida obligado en las investigaciones sobre los movimientos y movilizaciones sociales por la educación dinamizadas por actores educativos y, especialmente, por educadores y jóvenes universitarios. Desentrañar esta conexión es central para comprender los modos como se producen las relaciones de los actores movilizados con la política y para reconocer las demandas en la configuración de subjetividades políticas que logren instalarse como alternativas a las formas clásicas e instituidas del sujeto político moderno.

Partimos de afirmar que la pregunta ¿qué es la política? no ha perdido vigencia. Se trata de una discusión compleja, conflictiva e inacabada, como su contenido mismo. En este marco, la producción de las subjetividades políticas remite necesariamente al desentrañamiento de las formaciones sociales específicas de cada época, porque el vínculo entre sujeto y política tiene un trasfondo eminentemente social e histórico y no puede ser pensado sin una dimensión temporal y espacial que dé cuenta de las transformaciones histórico-sociales. Se trata de una relación dinámica, cambiante, en movimiento constante, que no puede ser preestablecida de una vez y para siempre; en consecuencia, no podemos hablar de una esencia estática e inmutable del sujeto ni de la política. Tanto el sujeto como la política son abordados aquí como categorías complejas, históricas y cambiantes, por tanto, posibles de ser transformadas.

Esta primera afirmación problematiza el paradigma hegemónico de la modernidad desde el cual la naturaleza y la razón de ser de la política deja de ser objeto de controversia. Para Foucault (1992), la teoría del contrato social hace parte del discurso filosófico-jurídico del liberalismo que justificó la intervención de dispositivos que ponen en circulación un determinado saber sobre el sujeto; por ejemplo, el discurso de la Ley habla sobre una voluntad general soberana que se materializa en el poder del Estado y a través de este impone los principios jurídicos y normativos de organización de la sociedad moderna. Siguiendo la argumentación de este autor, la política como consenso y proyecto de orden social disfraza la dominación dándole un estatus natural a este hecho histórico. 
En efecto, desde el derecho de soberanía y la idea de un contrato social racional y voluntario, es posible ocultar los procesos de sujeción que implica un poder disciplinario y normalizador que opera desde el Estado. Este poder político se dirige a la fabricación de sujetos obedientes que interioricen las normas, las órdenes y los valores sin necesidad de coerción y sin posibilidad de transgredirlas.

La política, situada en el poder constituido del Estado racional moderno, emana del consenso racional de los individuos, quienes aceptan una sumisión contractual voluntaria que implica una delegación o transferencia de su poder constituyente (condición política primaria) a cambio de derechos y garantías individuales en un marco normativo y jurídico específico. Desde una perspectiva estrictamente formal y normativa, la política vista desde el poder del Estado integra y somete, al mismo tiempo, al conjunto de individuos a un determinado proyecto de sociedad y su respectivo ordenamiento jurídico.

Bajo el primer aspecto, [la integración] vincula a los individuos a un sistema de relaciones sociales que tiene como fundamento la división social del trabajo, y permite la cohesión de las clases, los estratos y los grupos dominantes alrededor de las instituciones pú- blicas. Bajo el segundo [sometimiento], subordina al resto de la sociedad al buen funcionamiento del orden que constituye, y controla las prácticas sociales que son disfuncionales; en tal sentido, resuelve o mantiene latentes los conflictos y las contradicciones sociales sin alterar la estructura de dominación (Múnera, 1994, pp. 16-17).

En efecto, la política vista como consenso y proyecto de orden social integra y somete a los individuos a un sistema de relaciones y posiciones sociales que se formaliza a tal punto que se convierte en una estructura de dominación. Este reconocimiento sitúa y proyecta nuestras apuestas investigativas en la perspectiva de producir pensamiento crítico desde América Latina que pueda dar cuenta de las singularidades de los sujetos y movimientos de la región y ponga en cuestión las formaciones discursivas hegemónicas que, al actuar como regímenes de verdad, han privilegiado una determinada relación o identidad política del sujeto, otorgando un origen incuestionable a un modo de ser y estar en el mundo sobre otros mundos posibles, no reconocidos, excluidos y/o sometidos.

En este orden, la proyección se ubica en un horizonte emancipatorio y decolonizador que supere 
los cánones europeos de civilización'. Significa que la apuesta subyacente a nuestras investigaciones se sustenta en la premisa: otro mundo es posible y su reconfiguración exige sujetos políticos con capacidades para pensar, actuar y construir lo social y lo político desde otras maneras.

\section{Acercamientos a la categoría de subjetividad política}

Las siguientes premisas actúan como referentes para la comprensión y usos de la categoría de subjetividad política en procesos investigativos y en el agenciamiento de procesos emancipatorios.

\section{Premisa uno}

La noción de sujeto y de sujeto político requiere ser pensada históricamente y ampliarse más allá de la noción moderna.

Pensar al sujeto históricamente, es decir, en un tiempo-espacio determinado y en el marco de un proyecto de sociedad a construir, exige comprender que el sujeto es producido socialmente y que su autoconstitución pugna entre dos campos: lo instituido y lo instituyente. Este es un aspecto en el que coincidimos con varios investigadores, partimos del reconocimiento de los efectos de la matriz liberal moderna en la configuración de una noción restringida del sujeto, de subjetividad y de política, en la tendencia determinista de sujeción y dependencia del sujeto a las estructuras, en su nominación y definición como agente funcional y reproductor del orden social establecido. Aquí, como hemos dicho, la política no solo integra, sino que somete al individuo al orden social hegemónico, restringe su autonomía y su poder instituyente.

En el actual contexto de la sociedad capitalista y del mercado como referencial de la política neoliberal, se sitúa una noción de sujeto coincidente con su definición etimológica: subjectus, sujeto a, sometido a los dispositivos de sujeción, disciplinamiento, heredados de la modernidad. Se ubican aquí las tecnologías

Desde el enfoque decolonial se amplía la mirada de las relaciones centro-periferia de los mal llamados países del tercer mundo con occidente. Hoy, los movimientos antiglobalizadores están agenciados por actores del llamado tercer mundo, muchas de estas expresiones se emplean en el Foro Social Mundial. 
normativas que condicionan y fijan la identidad política del sujeto al reconocimiento constitucional, donde lo jurídico opera como un mecanismo de normalización de lo político.

Para el caso de las experiencias estudiadas con jóvenes y maestros, evidenciamos los efectos del dispositivo legal que se manifiestan en el imperio y la magnificación de la Ley y el miedo a la sanción; la Ley opera como una tecnología normativa que convierte la política en una estructura rígida que normaliza, asigna y fija roles $y$ funciones a los agentes sociales y no permite pensar ni hacer nada más allá de ella. Esa imagen rígida y formal de la política interiorizada a través de la Ley sobresale, para el caso de los maestros, en la implementación de la Ley 715 de 2001 y los decretos reglamentarios que impusieron límites a sus acciones por miedo a la sanción. El control legal se instaló desde regulaciones que buscaron paralizar en todas sus expresiones su acción política, sujeción que en el caso de los maestros oficiales se espera que se acepte y exprese como condición naturalizada para el ejercicio de su rol y que asuman posturas de subordinación y funcionalidad al orden social existente ${ }^{2}$.

2 En efecto, las políticas públicas impuestas en el campo de la educación y la instalación, en términos de adopción y adaptación, de las macropolíticas internacionales a los contextos nacionales se materializaron en leyes y planes sectoriales, en sintonía con las políticas de reforma y ajuste estructural de lo estatal. Esta tendencia ha caracterizado "la estrategia de desarrollo", no solo en Colombia, sino en la mayoría de los países de la región (Martínez, 2004).
Tales discursos operan a través de un conjunto de narrativas y prácticas, principalmente políticas y económicas, que se codifican como "preceptos y recetas que han logrado fundarse, racionalizarse y justificarse teóricamente" (Foucault, 1980). En otras palabras, el problema está relacionado con los modos en que estos instrumentos, que actúan como referenciales de política (sistema de ideas y creencias), logran traducirse y materializarse en el ordenamiento social educativo. Aquí cobran sentido las palabras de Boron cuando afirma que "las reformas padecidas por nuestras sociedades en las últimas décadas son, en realidad, crueles 'contra-reformas' y acentuados procesos de involución social" (2004, p. 19). En el caso colombiano, aunque la Ley 715 de 2001 no expresa ni materializa la reforma o la contrarreforma educativa en toda su extensión, es una expresión significativa de este proceso.

Desde el referencial del mercado, la escuela es reducida a un apéndice de la empresa capitalista y se posiciona como campo efectivo y eficaz para la formación y producción de cuerpos socialmente productivos; de este marco se espera que las instituciones educativas operen como dispositivos de gobierno, disciplinamiento y subjetivación que incidan, formen, condicionen, direccionen. En suma, que produzcan subjetividades para un determinado modo de ser y estar en el mundo. 
Este primer marco interpretativo de la subjetividad política puede leerse desde los modelos posfigurativos de socialización de los que habla Margaret Mead (1997), que se inscriben y se reproducen de manera funcional al modelo cultural dominante. Para este modelo de socialización, la subjetividad se transmite, se hereda, es inmutable. Es precisamente esta primera noción de la subjetividad política la que se convierte en objeto de problematización en nuestras investigaciones y la que anima la búsqueda de construir o desentrañar puntos de fuga que actúen como otros modos instituyentes de subjetividad, que muchas veces operan en los mismos escenarios instituidos.

\section{Premisa dos}

Pensar la categoría de subjetividad política exige desafíos que posibiliten establecer otros vínculos con las nociones de la política y lo político.

Es claro que las formaciones discursivas inauguradas con el proyecto hegemónico de la modernidad no solo han llenado de contenido los conceptos de sujeto y de política, sino que le han dado consistencia a una forma de pensar este vínculo en el que se establece una relación de correspondencia funcional e irreflexiva entre sujeto y estructura; una relación construida a partir de una concepción rígida y normativa que niega el carácter dinámico y mutable de la política.

El arriesgo necesario para tomar distancia de los efectos de la matriz liberal moderna y establecer otros vínculos con la política implica asumir, al menos, los siguientes desafíos:

\section{Reconocer una visión más amplia de la política}

Exige ir más allá de la noción de política reducida a la formaEstado y a su aparato: el Gobierno, o, simplemente, a la acción de los denominados profesionales de la política, materializada especialmente a partir de la formulación y ejecución de planes y programas.

La apuesta, como plantea i ek, es por posicionar una comprensión de la política como una multitud de actos de vida que comprometen la totalidad social, el trabajo, la cultura, el Estado, lo público y el pensamiento. Desde este planteamiento, la política no solo produce un resultado en el marco de relaciones existentes, también 
cambia el marco que determina el funcionamiento de las cosas. En esta lógica, la política es concebida "no solo como el arte de lo posible, que bien podría asociarse a la realpolitik del liberalismo, sino que constituye el arte de lo imposible, en el que juega la imaginación, la creatividad, la sapiencia popular y la dis-utopía" (Gantiva, 2003, p. 169).

Frente a la tendencia dominante a la absorción semántica del concepto de política, el sentido que aquí se quiere significar es el de la política como capacidad instituyente, que, instalada en el sujeto, contribuye a mantener activa la conflictiva y nunca acabada construcción del orden deseado (Lechner, 1986). Postura y noción que instala al sujeto como centro de acción política porque lo hace visible como inherentemente político y porque posibilita pensar la política como subjetividad y como producción subjetiva; es decir, como el arte y la disposición de construir, además de lo posible y lo deseable; donde tienen cabida la memoria, la resistencia, la imaginación, la creatividad, la utopía, la multiplicidad de saberes y experiencias que organizan nuestra existencia individual y colectiva ${ }^{3}$.

La tensión instituido/instituyente, conceptos propuestos por Castoriadis, es constitutiva de la significación que se quiere dar a la noción de política. Para Castoriadis (2001),

Postura y planteamientos que se sustentan en los escritos de Castoriadis y que se amplían en el trabajo de Martínez (2008) y Cubides (2012). la política se concibe como una actividad colectiva reflexiva y lúcida, un proceso permanente de autoinstitución de las significaciones sociales imaginarias. Sustentada en el imaginario social instituyente, la política reivindica la imaginación radical y el poder de creación y transformación inmanente, tanto a las colectividades como a los seres humanos singulares. La mutabilidad de la política como proyecto de autonomía reivindica, como propone Castoriadis, su inagotable capacidad de resistir, cuestionar y transformar el orden social instituido.

Hasta aquí, es preciso distinguir entonces entre lo político instituido y la política instituyente. La política, concepto que nos interesa dilucidar, es un proyecto de autonomía, es una actividad tanto individual como colectiva, reflexiva, conflictiva y nunca acabada que está en movimiento continuo, y cuando se intenta formalizar o fijar su contenido de manera estable, se diluye, se desvanece, queda subsumida en medio de lo político, convirtiéndose en una estructura de poder. La política está siempre en medio de esta tensión constitutiva entre lo instituido y lo instituyente, su propósito es crear los proyectos y las instituciones imaginadas, para que una vez construidas e "interiorizadas por los individuos, faciliten en lo más posible el acceso a su autonomía individual y su posibilidad de participación efectiva en todo poder explícito existente en la sociedad" (Castoriadis, 1988, p. 21). 
Hasta aquí podemos afirmar que es posible repensar y asumir la política desde otros referentes, lugares y acciones instituyentes, ejercida por sujetos dotados de autonomía, creatividad y con apuestas por otros órdenes sociales a construir. Subjetividades políticas que se vienen reconfigurando desde otras matrices de pensamiento y acción y desde otros escenarios de actuación. Aquí tienen lugar las movilizaciones por la educación como escenarios de subjetivación política.

\section{Reconocer que la subjetividad política no puede definirse} en oposición radical a las prácticas políticas tradicionales

Siguiendo la argumentación de Castoriadis, afirmamos que la subjetividad política está inscrita en un campo de fuerzas que expresa la permanente tensionalidad entre lo instituido y lo instituyente. No hay instituido separado de lo instituyente, estas dos líneas de fuerza están en pugna permanente en el mismo campo social; lo instituyente sucede en medio y dentro de lo instituido porque nadie está totalmente por fuera de las reglas que configuran el imaginario social dominante, siempre se está expuesto y permeado por las estructuras es sus múltiples expresiones.

Cabe aclarar aquí que lo instituido no se reduce solamente al gobierno ni a las forma-Estado instauradas especialmente desde sus instituciones, estas son solo algunas de sus expresiones; lo instituido hace alusión a la fuerza hegemónica de los poderes dominantes que garantizan el estado de las cosas, aquí está incluida la economía, la política, la organizaciones, la familia, entre otras. Aparatos y mecanismos de sujeción y dominación que operan en y desde la sociedad en su conjunto y que portan mecanismos de reproducción culturalmente establecidos.

Aparece entonces una segunda comprensión de la noción de sujeto que exige transitar desde el paradigma del sujeto-objeto, del sujeto que demanda intervención política hacia una comprensión más compleja del sujeto que permita evidenciar su capacidad de producción subjetiva, su capacidad de co-figurar y pre-figurar en los sentidos que explicita Margaret Mead en su obra Cultura y compromiso. Nos referimos a la necesidad de producir nuevos sentidos desde referentes no experimentados o no evidenciados con anterioridad.

Es en esta segunda comprensión de la noción de sujeto que podemos afirmar que la ausencia de una relación explicita de los sujetos (maestros y jóvenes) con las clásicas y socialmente reconocidas 
categorías de la política, o su negación explícita, no equivale, como se afirma cotidianamente, a una despolitización o condición apolítica de los sujetos. Por el contrario, se anuncia una visión más amplia de la política que crea la necesidad de visibilizar y agenciar modos emergentes de subjetivación. Exige indagar por saberes, prácticas y experiencias de producción subjetiva que se visibilizan en las resistencias, las protestas, las movilizaciones, prácticas emergentes o de frontera que se configuran como contraculturales y contrahegemónicas a los modos de pensar y orientar las acciones sociales, educativas en el caso que nos ocupa, que muchas veces suceden en los mismos escenarios instituidos, pero que es necesario reconocer como instituyentes.

En las investigaciones que hemos adelantado se pone en escena la tensión que subyace entre las dos líneas de constitución y formación de los sujetos políticos en el campo de la educación: la instituida como poder dado, y la instituyente como capacidad y como poder a construir, aclarando que la forma instituida-dominante de pensar y actuar no establece un cierre de lo social, sino que es posible, individual y colectivamente, cambiar ese pensamiento instituido en el campo de lo instituyente-alternativo. En suma, pensar la dialéctica instituido/instituyente exige una lectura relacional y constructiva de la realidad social; como hemos dicho, por tratarse de dinámicas sociales, lo instituido y lo instituyente no puede pensarse de manera desarticulada ni excluyente, porque cuando el imaginario instituido (lo político) absorbe, neutraliza o niega lo instituyente, la política se desvanece.

\section{¿Qué noción de subjetividad política?}

Recapitulando, es posible precisar algunas comprensiones sobre esta noción. El sujeto, como hemos planteado, no es una esencia, no tiene una identidad preestablecida; el sujeto implica un modo de ser y estar, una multiplicidad de acciones y posiciones y una producción social. Como problema sociológico, el sujeto no es el lugar de la plena libertad que defienden los subjetivistas, ni el de la plena sujeción, como argumentan los funcionalistas. El sujeto es potencia, posibilidad, poder constituyente, resistencia, voluntad de acción, solidaridad, pero también es debilidad, egoísmo, poder instituido, función social. Está inmerso en un campo de fuerzas, en el conjunto de relaciones e interacciones que establece con el entorno, con su sí mismo, con procesos institucionales locales y globales, que lo estructuran permanentemente desde una multiplicidad de vectores de subjetivación: la necesidad, el deseo, las pulsiones, los instintos, el interés, el lenguaje, las leyes, el pensamiento, la voluntad, los sentimientos, los proyectos, entre otros. 
Reconocer esta doble connotación del sujeto, de un lado, socialmente producido por dispositivos y prácticas de poder, individuos y colectivos conectados y sujetados a formas y lógicas que lo determinan, y de otro, como producción subjetiva con capacidad de prefigurar, expresando las oposiciones, las resistencias, la creatividad y la capacidad de agenciar transformaciones, permite definir la subjetividad como el universo intrínseco del sujeto, de su producción social y de su producción política, como voluntad e intencionalidad de un sentido particular de existencia individual y colectiva.

La subjetividad no viene dada, se produce socialmente de manera constante y remite a la corporeidad del sujeto en todas sus dimensiones. Por tanto, si las instancias de subjetivación no están totalmente establecidas, porque la subjetividad "no conoce ninguna instancia dominante de determinación que gobierne las demás instancias como respuesta a una causalidad unívoca" (Guattari, 1996, p. 11), entonces no es posible referirnos a un modo único de subjetividad porque esta emerge y se configura en múltiples circunstancias: en medio de contingencias, modos transitorios de vida, luchas permanentes, entre el deseo, las presiones sociales y las necesidades de vivir y sobrevivir.

Desde esta mirada, la subjetividad política es producción de sentido y condición de posibilidad de un modo de ser, estar y actuar en sociedad; de asumir posición en esta y de hacer visible el poder para actuar. Posición que está inscrita en un campo de fuerzas complejo que exige al sujeto deconstruirse y reconstruirse permanentemente en la tensión constante entre lo instituido y lo instituyente. Tensiones que coexisten modos de producción heredados, hegemónicos, junto a modos prefigurativos de la subjetividad y en la lucha permanente por configurar desde otros horizontes de pensamiento y acción, porque como hemos insistido, la subjetividad política se configura en medio de la política tradicional o convencional y los modos de producción emergentes.

Entonces, si la subjetividad es plural y polifónica, y producida desde múltiples instancias y escenarios -individuales y colectivos-, trabajar la categoría de subjetividad política en procesos investigativos exige redefinir lo político, aquello que constituye a los sujetos políticos y reconocer o reconfigurar acciones y escenarios de subjetivación. 


\section{Pistas para la configuración de subjetividades políticas}

Hemos dicho que pensar la cuestión del sujeto político y la producción de subjetividades políticas contemporáneas exige una aproximación crítica tanto a los contenidos subjetivos como a los dispositivos de poder que buscan imponer un modo determinado de producción de sociedad y de sujetos. Por tanto, acercarnos a comprender los requerimientos en la configuración de subjetividades políticas demanda identificar algunos factores que estructuran y determinan la condición cosificada del sujeto, a fin de dilucidar desde dónde es posible agenciar el "darse constituyente", en oposición con lo que hoy lo determina y en perspectiva de activar otros pliegues de su subjetividad.

Se esbozan a continuación algunas pistas, conceptuales y metodológicas, para el uso de la categoría de subjetividad política en procesos investigativos: rupturas y desafíos y planos de fuerza como categoría analítica y metodológica.

\section{Rupturas y desafíos}

La primera ruptura, y a la vez desafío, se sitúa en la tensión y disputa entre lo determinado y lo indeterminado. Se relaciona con la necesidad de reconocer las posiciones presentes de sujeto con la intención de posibilitar el desentrañamiento de las limitantes existentes para abordar las "acciones de despliegue" que necesita asumir en su reconfiguración. Estudiar la subjetividad es también una posibilidad de contribuir a romper las barreras de sujeción instaladas en el sujeto que coartan la capacidad de producir emociones, pasiones, decisiones y riesgo para enfrentar nuevas acciones.

Este proceso de deconstrucción pasa por indagar acerca de los referentes que lo determinan en contraste con las nociones de autonomía, política y sociedad a construir. Aquí es necesario el reconocimiento de la historia personal del sujeto, sus interacciones con el contexto, con la cultura y, en general, con los espacios de subjetivación que lo han determinado para situarlos en tensión y disputa con los desafíos constituyentes. Esta primera labor de autoconstitución hace visible los determinantes del orden instituido frente a los que es necesario rebelarse. Tarea que no es fácil si se tiene en cuenta que los sujetos con quienes hemos interactuado en los procesos investigativos, los maestros y los jóvenes, están expuestos y sujetados directamente a los modos de regulación del régimen imperante ${ }^{4}$. Sistema que, al estar regulado por el mercado, necesita y legitima la actitud pasiva, apática y acrítica de los

\footnotetext{
4 De los maestros se espera una actitud acrítica y reproductora; de los jóvenes se espera que se formen directa y acríticamente en las competencias necesarias para actuar como agentes de consumo.
} 
sujetos y afirma la producción de subjetividades funcionales a las relaciones de explotación y subordinación.

La segunda ruptura remite a la sustancia del sujeto, a su reconocimiento como sujetos de necesidades y de posibilidades. Necesidad de conocerse, construirse e interpretarse, que le deviene en posibilidad de asumirse constructor de su propia historia, acción que está atravesada por preguntas a su sí mismo constituyente y que indagan por el plano existencial: ¿Quién soy? ¿Cuál es mi lugar social y político? ¿Qué relaciones establezco entre lo que hago y lo que quiero ser y hacer? Expresiones que nos conectan con una noción de sujeto en búsqueda de completitud y afirmación, un sujeto de experiencias. De posibilidad, porque un sujeto que se pregunta por su existencia y devenir se coloca en el plano de lo instituyente; así, el reconocimiento de las necesidades le permite objetivarse, situarse en su lugar presente y repensarse en lo por-venir, en lo posible por construir, proceso que es permanente, pero no lineal.

El tercer desafío remite a la necesidad de un saber sobre sí mismo, su mismidad. Saber que no es solo racional, sino que está cruzado por lo sensorial. Las expresiones: estar consciente, ser consciente de algo, remiten a la subjetividad y dan cuenta de que es imposible disociar mente-cuerpo, pues la conciencia opera en un cuerpo vivo que se experimenta como tal y remite necesariamente a los sentidos. Entender y potenciar la formación de la subjetividad impone al sujeto la necesidad de definirse con respecto a sí mismo, al hecho de que saberse es sentirse, y en ello quedan comprometidos conciencia, sentido y sensación, allí se funda el yo; como subraya Morin (2001), "en el sí, en la entidad corporal, están incluidos el yo y el mí".

Estudiar la subjetividad remite entonces al reconocimiento y comprensión de las experiencias subjetivas del sujeto, no solo a la exterioridad, la mirada investigativa exige acercamientos y metodologías que permitan y produzcan reflexión y autorreflexión. Acciones que posibiliten que el sujeto se reconozca en su emocionalidad, en su mismidad, en su dimensión metacognitiva; objetivarse para poder mirarse a sí mismo y dar lugar a construcciones emergentes. Proceso que Mead (1982) denomina "self", "sí mismo", reflexivo que indica lo que puede ser al propio tiempo sujeto y objeto. Esto es, la capacidad autorre- 
flexiva del sujeto para reconocerse y transformar su sí mismo ${ }^{5}$.

La cuarta ruptura remite a la necesidad de repensar los escenarios de subjetivación política. La mirada empírica, las interacciones y aproximaciones investigativas adelantadas por más de una década con redes, colectivos $y$, en general, con experiencias de acción colectiva en sus diferentes expresiones y modalidades nos permite plantear que los ámbitos de nucleamiento y los procesos organizativos se convierten en espacios instituyentes para configurar o afirmar la dimensión política -individual y colectiva- de los sujetos. Las razones son múltiples, baste decir que en estos escenarios se favorece la libre expresión, la pregunta, la duda, la crítica, los actos creativos que devienen de una dimensión estética potenciada.

En estos espacios se minimizan las inseguridades, se desarrolla la confianza al compartir deseos, necesidades, apuestas y logros. A su vez, estos procesos personales sirven de plataforma para potenciar acciones políticas de mayor envergadura (Martínez, 2008).

Mead (1982), en su texto Espíritu, persona y sociedad, señala que "espíritu y persona" son emergentes sociales, y que el lenguaje proporciona el mecanismo para su emergencia, "la persona es algo que tiene su desarrollo; no está presente inicialmente, en el nacimiento, sino que surge en el proceso de la experiencia y la actividad sociales. (...) La persona tiene la característica de ser un objeto para sí, y esa característica la distingue de otros objetos y del cuerpo (...) esta característica está representada por el término "sí mismo", "self" (pp.168-176).
Acopiando lo dicho, la subjetividad establece una relación intrínseca entre razón-concienciasentimiento-emoción-cuerpo y se enuncia en la experiencia del sujeto y en las formas de acción que devienen de su concienciación. A su vez, si el sujeto se configura en y desde sus interacciones, la pregunta por su constitución remite directamente a indagar por los escenarios y espacios de subjetivación instituyentes, a las representaciones, relaciones, acciones e interacciones que le posibilitan afirmarse como sujeto individual y colectivo.

\section{Planos de fuerza como categoría analítica y ruta metodológica}

Los planos de fuerza que contribuyen a esa mirada exploratoria y constitutiva de subjetividad política, promovidos en escenarios de acción colectiva, son: lo agenciante, lo potenciado y las resistencias (Martínez, 2008). Exploratoria y constitutiva porque las experiencias investigativas que documentan estos planteamientos se han trazado la doble intención: reconocer y potenciar subjetividades. Reconocer que es desentrañar, provocar modos de reflexión que coadyuven a descubrirse como sujetos en su mismidad, ello exige provocar momentos de introspección y autorreflexión para reconocer acciones, eventos y procesos subjetivantes; y, más allá de estos, 
para identificar las expresiones políticas de la subjetividad. Las fuerzas se asumen como vectores que están en movimiento y movilizan a los sujetos de las experiencias para provocar reterritorializaciones en los modos de subjetivación y en los escenarios instituidos e instituyentes en que se producen estas configuraciones subjetivas.

La noción de planos de fuerza vinculada a la constitución de subjetividades políticas se utiliza en dos dimensiones: como unidades de exploración y análisis y como ruta metodológica. Como unidades de análisis porque las acciones y expresiones que dan cuenta de las movilizaciones en el sujeto, en sus modos de agencia, potencia y resistencia pueden leerse en perspectiva analítica para desentrañar modos y expresiones de subjetivación política. También porque en las interacciones y luchas entre lo instituido-instituyente, estas categorías operan como matrices de transformación que provocan el redimensionamiento de las relaciones de saber-poder y se despliegan en las subjetividades como fuerzas constituyentes de la capacidad de acción política.

Como ruta metodológica porque se reconoce y propone un camino que no es estático, sino que tiene variantes y múltiples posibilidades constituyentes ${ }^{6}$. En las investigaciones realizadas, estos tres planos operan metodológicamente; además de su reconocimiento como categorías analíticas, con la identificación de campos de análisis, criterios metodológicos y con la adopción de la noción de caja de herramientas, se contribuye a la construcción de rutas metodológicas, que están abiertas para ser complementadas y continuadas.

\section{Como categoría analítica}

El siguiente esquema identifica tres categorías que operan como planos de fuerza: Agencia, Potencia y Resistencia.

Figura 1. Panos de fuerza

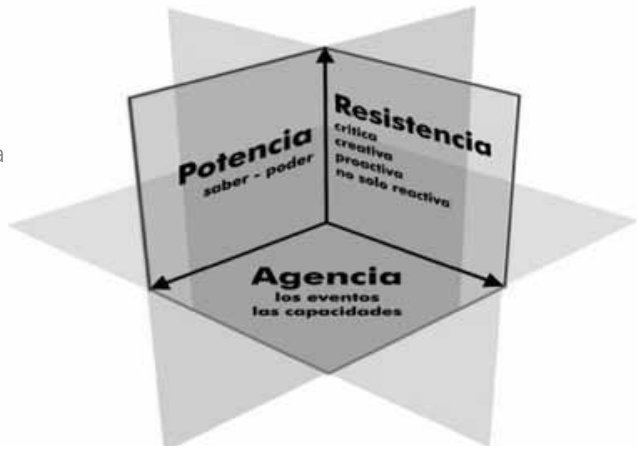

6 Las rutas metodológicas, así como las exploraciones y acercamientos a identificar y potenciar formas constituyentes de subjetividad no están acabadas, más bien podríamos decir que los acercamientos son múltiples y eso contribuye a poner en el centro de discusión esta categoría. 
Lo agenciante se refiere a aquello que apalanca, provoca o promueve el fortalecimiento de la capacidad política del sujeto; la hipótesis con que hemos abordado este concepto plantea que cuanto más amplia sea la capacidad de agencia, mayor será también la capacidad del sujeto para influir en los cambios sociales, culturales, políticos y para mejorar sus propias condiciones de vida.

En el plano analítico, hemos utilizado esta noción con una doble connotación: como capacidad y como evento. Como capacidad, que se traduce en una especie de fuerza, acción que se instala en el sujeto para activar, promover o posibilitar un aumento de su poder. Un poder para participar, disentir, movilizarse, resistir y para provocar una alteración en la cotidianidad. Alteraciones que son también alter-acciones, otras acciones, que suceden tanto en el plano reflexivo como en el de la acción. Como evento -o factor de agencia-, la mirada se realiza a acciones externas que son propiciadoras o movilizadoras para la emergencia o fortalecimiento de otras capacidades en el sujeto.

Agenciar es estar en el medio, en la línea de encuentro entre un mundo interior con un mundo exterior para provocar la capacidad de acción. Desde Aristóteles se hablaba de agencia referida a una potencia para la acción; en nuestro caso es asumida como la posibilidad de despliegue para otros modos de pensar y actuar. El agenciamiento no es entonces la sola articulación de acciones o interacción, sino lo que estas logren para provocar y animar la acción.

$$
\begin{aligned}
& \text { El agenciamiento no es } \\
& \text { la articulación (...), el } \\
& \text { agenciamiento pone en } \\
& \text { juego, en nosotros y fue- } \\
& \text { ra de nosotros, multiplici- } \\
& \text { dades, territorios, fuerzas } \\
& \text { de composición. Por lo } \\
& \text { tanto, no se trata de dos } \\
& \text { identidades en relación } \\
& \text { (...) sino de agenciamien- } \\
& \text { tos múltiples. El agencia- } \\
& \text { miento no se afirma en la } \\
& \text { concreción de un ideal, } \\
& \text { sino en la expresión de } \\
& \text { una potencia de actuar } \\
& \text { (Sztulwark y Duschatzky, } \\
& \text { 2005, p. 205). }
\end{aligned}
$$

En síntesis, llamamos agencia a aquellas fuerzas-acciones-expresiones que activan, promueven o posibilitan una alteración en la cotidianidad del sujeto, tanto en su forma de pensar como en las acciones que realiza y que producen un aumento de su poder.

Para ilustrar los modos como opera esta fuerza, citamos algunos eventos agenciantes: 1) Algunas formas de organización de los colectivos de maestros logran romper las formas verticales, el mito del poder representado y el carácter preestablecido de operar. Estas formas no uniformes logran redistribuir el poder, minimizar ansiedades, miedos e inseguridades. Al relacionarse de 
otra manera, más horizontal y sin escalas de jerarquía, se agencia y se estimula una relación y un reconocimiento de pares, un poder colegiado que produce empoderamiento compartido. 2) La interacción comunicativa, el clima de confianza y la acción entre pares, ayuda a los maestros a superar los miedos que albergan y que les impiden reconocer que no hay problema en decir "no sé", "no entiendo"; 3) Los lazos afectivos que se provocan y estrechan en algunas organizaciones de jóvenes y maestros cohesionan y crean entramados que fortalecen la decisión y la voluntad de acción colectiva. Esto porque está comprobado que el ángulo físico se adapta más rápido que el ángulo mental, ya que lo ontológico requiere mayores esfuerzos de apropiación y concienciación.

Lo potenciado. "La potencia es algo que mi cuerpo puede", "es la potencia de mi cuerpo", decía Spinoza, entonces la potencia es fuerza, capacidad, voluntad de poder que se instala en el sujeto y que es producida y producente de una relación directa que se traduce en una posibilidad mayor de reflexionar, reaccionar y actuar. Entonces la potencia es poder y ayuda a la conquista del poder, pero no un poder cualquiera, sino un poder-saber actuante que se instala en el sujeto y activa su poder de decisión y capacidad para actuar. En el caso de los maestros, poder para intervenir en la toma de decisiones, en la defensa de lo público, en la definición de currículos pertinentes al contexto y a las exigencias de formación de los educandos, en la construcción de políticas educativas, entre otras acciones.

En el caso de los jóvenes, la condición política potenciada se expresa en formas de nucleamiento y configuración de identidades colectivas donde el arte, por ejemplo, se ratifica como una vía privilegiada para producir sentidos y reflexiones sobre sus realidades. La universidad se revela como un campo estratégico de subjetivación, múltiple y complejo. El interés por la política emerge en la búsqueda por conectar su experiencia estudiantil con la realidad. La experiencia universitaria, afirman los jóvenes estudiantes indagados, no es solo academicismo, teorización, se manifiesta en una sensibilidad con su entorno, con un modo de ser y estar en su contexto social. Aquí reconocemos que la universidad no solo se sitúa en dirección de las fuerzas instituidas-hegemónicas ${ }^{7}$, también es el espacio de producción y formación de fuerzas instituyentes, de formación de deseos sociales y producción de sentidos alternativos.

La micropolítica de la universidad opera y se materializa en los currículos, las prácticas de evaluación y el establecimiento homogéneo de los logros de los estudiantes; los logros se estandarizan para mostrar resultados, es decir, se homogeneizan los productos, y de ahí un determinado modo de ser sujeto estudiante y vivir la experiencia universitaria. 
Otros ejemplos de expresiones de una subjetividad política potenciada en escenarios de acción colectiva son: el conocimiento y la interacción con realidades sociales; la capacidad para repensar, reconfigurar problemas y construir alternativas de solución viables; la activación de un modo de independencia y de libertad en la definición y ejecución de las prácticas pedagógicas y de alteración de los currículos preestablecidos; el fortalecimiento del pensamiento y la acción crítica y proyectiva; el incremento de acciones solidarias, de sensibilidad y responsabilidad social y de la decisión para participar en instancias de decisión, en escenarios de construcción de política.

La resistencia se asume como una capacidad instalada en el sujeto. Capacidad porque se instaura en los mismos sujetos potenciales del cambio, su fundamento está en sus formas de pensar y actuar, su expresión está en la transformación que se opera en sus formas de acción, en sus prácticas y experiencias.

Resistir remite a aquellas fuerzas que se movilizan e instalan en la subjetividad para provocar la acción crítica y la emergencia de nuevas acciones. Fuerzas que operan en el adentro y afuera, en la trama y en la estructura; afuera para ser capaces de leer y comprender críticamente las realidades y replantear nuevos horizontes de sentido, adentro para efectuar los cambios necesarios y poder pensar y actuar desde lógicas instituyentes. Se trata de una resistencia crítica proactiva, no necesariamente reactiva ni violenta; su carácter proactivo actúa cuando las fuerzas que constituyen las resistencias se materializan en propuestas de cambio, en formas precisas de incidir en las instancias de decisión y de poder. Desde su propuesta en multitud, Hart y Negri plantean que la resistencia hoy se sustenta al menos en tres principios: 1) atender la oportunidad histórica de resistir contra todo lo que se impone; 2) establecer correspondencia entre las formas de resistencia y las transformaciones económicas y sociales, y 3) apuntar a la democracia y la libertad corrigiendo las formas de actuación no democráticas.

La resistencia se asocia a pensar vías alternas a las lógicas instrumentales, a buscar opciones para salir del individualismo, aunque todo apunte a que se mantenga la insularidad del sujeto, a vincularse a proyectos alternativos aunque se diga que no hay nada que hacer. En este orden, los maestros y los jóvenes, cuando se colectivizan para la acción, actúan como sujetos que resisten y que provocan resistencias actuando en escenarios convencionales y no convencionales para erosionar lo hegemónico. Acciones que muchas veces se leen en clave de lo instituido y que exigen ampliaciones en la mirada investigativa.

Asumimos entonces la resistencia como una noción compleja y multidimensional, como una capacidad política que implica el desarrollo de otras capacidades, una posición de 
fuerza que posibilita movimientos en lo establecido y como un elemento sustancial a todo proceso de cambio social. Por tanto, las expresiones de resistencia pueden leerse como fuerzas orientadas a reconocer y desestructurar lo instaurado como "orden impuesto", a superar los límites y las limitantes que buscan cooptar la condición de sujetos.

\section{Como ruta metodológica}

Con lo dicho hasta aquí, podemos afirmar que potenciar la emergencia de subjetividades políticas múltiples y diversas exige crear condiciones para hacer posible el principio de poder constituyente en el que se haga efectiva la participación de los mismos sujetos en los procesos de creación permanente de la experiencia política y de la subjetividad. También exige reconocer que la capacidad de acción política del sujeto se potencia en el conjugar de experiencias mediadas por la reflexión crítica y en tensión permanente con un proyecto que represente la utopía deseable y posible.

Las dificultades se presentan especialmente porque no es posible partir de una ruta pre-elaborada, rígida y predefinida; también porque investigar acerca de las subjetividades no remite a hablar de ni desde los sujetos, sino con ellos y ellas. También porque el estudio de la subjetividad no depende solo de los reconocimientos empíricos, aunque requiere de esos rasgos de expresión directa; la construcción de conocimiento se funda en la indagación empírica, pero necesita superar las miradas descriptivas y prescriptivas, los modelos o enfoques con pretensiones evaluativos. Investigar acerca de la constitución de subjetividades no es fácil si se quiere superar la acción y la intención de "objetivar los sujetos", aunque lo objetivo y subjetivo se imbrican en su producción. Significa que la mirada no puede hacerse por fuera de los mismos sujetos de investigación, sino desde adentro y con ellos mismos, porque los flujos de la interacción y los resultados no operan solo a nivel analítico para producir conocimiento, la mirada también se experimenta a favor o en contra de sus propias acciones e interacciones.

Podríamos decir entonces que las investigaciones sobre la subjetividad tienen un carácter singular. Se ubican en el paradigma cualitativo y navegan entre los enfoques interpretativo-hermenéutico y crítico-social ${ }^{8}$. Y entre esas tensiones y relaciones, preferimos

8 El enfoque crítico, social y transformativo asume las perspectivas decoloniales, interdisciplinarias y transformadoras trazadas en América Latina por autores como González Casanova, Quijano, Mignolo, De Sousa, entre otros. 
adoptar las nociones de: campos de análisis y criterios metodológicos.

\section{Campos de análisis}

La exploración y abordaje de la noción de subjetividad política nos ha permitido identificar por lo menos tres campos para el análisis y la interpretación de los hallazgos que tienen estrecha relación con los planos analíticos acabados de enunciar y están interrelacionados en su uso investigativo. Estos son: a) los efectos de la tensión instituido-instituyente en la producción de subjetividades; b) los procesos de reflexividad: autocomprensiones del sujeto en las dimensiones metacognitiva y volitiva, y c) los principios de producción, transformación y proyección como descriptores constitutivos y estructurantes de subjetividad política.

El primero de estos campos, los efectos de la tensión instituido-instituyente, ya han sido precisados en la primera y segunda parte del texto. Efectos que ponen el énfasis en el antagonismo y la lucha de fuerzas a la hora de definir la política y aquello que define a los sujetos políticos y que suponen una consideración de fondo que no debe ser dejada a un lado: construir el mapa de las tensiones intrínsecas y las líneas de fuerza constitutivas del campo donde se configuran y reconfiguran las relaciones entre sujeto y política.

El segundo hace referencia al reconocimiento de las emergencias constituyentes de subjetividad. Citamos entre estas la exploración y afirmación de la dimensión metacognitiva y volitiva. A la dimensión metacognitiva: autoimagen, autoconciencia, procesos que, como plantea De Sousa (1998), van más allá de las ideas de autonomía y libertad, porque la subjetividad involucra las ideas de autorreflectividad, autorresponsabilidad, particularidades potencialmente infinitas que le imprimen un sello propio al sujeto, que lo enriquecen y le abren nuevos horizontes de autorrealización y compromiso. A su dimensión volitiva, entendida como aquello que lo expresa y potencia su voluntad de acción, voluntad que es poder y que se asume como "una capacidad mayor, un motor para la acción que se instaura en el sujeto como fuerza inmanente pero que exige fortalecimiento para rebelarse ante las frustraciones, fortalecer y afirmar la visión proyectiva y las utopías viables" ${ }^{\prime \prime}$ (Martínez, 2008).

El tercero remite al reconocimiento de los principios de producción, transformación y proyección, que pueden leerse, de un lado, como categorías constitutivas de subjetividad política, en cuanto capacidades que se instalan en el sujeto desde los planos de lo agenciante y lo potenciado; de otro, como expresiones de acción política, en las que se incluyen los modos de resistencia.

9 Algunas expresiones de la dimensión volitiva son: persistencia en el alcance de propósitos, deseo permanente de cualificación, incremento de la capacidad para decidir por sí mismo, para expresar sus posiciones, sus propias ideas. 
Producción, que puede ser leída como capacidad que se instala en el sujeto y da cuenta de sus formas de individuación y experienciación, dos procesos que lo configuran y expresan como productor. En las reflexiones y en la mirada individual y colectiva a la cotidianidad de los sujetos es posible reconocer su capacidad para actuar como productores y gestores de iniciativas: proyectos, planes y propuestas alternativas, entre otras acciones.

Transformación en los planos personal, profesional, social y político del sujeto. Este principio, en los sujetos maestros, se hace visible en la comprensión del papel político de la educación, en el convencimiento que cada sujeto tiene acerca de la necesidad de trabajar por el buen vivir de sus pares, sus estudiantes y, de manera más amplia, de la sociedad, en la necesidad manifiesta de trascender y superar los planos de subordinación, también en la decisión de transitar de una participación delegativa a una participación activa y auténtica.

Proyección, que es también prospección y que se expresa como una actitud y apertura que lo impulsa a la incursión en proyectos que se avizoran como relevantes, a persistir en el alcance de los desafíos y propuestas que emprende, también, en la necesidad de participar en procesos y acciones colectivas.

\section{Referencias}

Acosta, F., Cubides, J. \& Galindo, L. (2011). Sentidos y prácticas políticas en el mundo juvenil universitario. Bogotá: Universidad Nacional de Colombia, Facultad de Derecho, Ciencias Políticas y Sociales. Vicedecanatura de Investigación y Extensión.

Berger, P., \& Luckmann, T. (2006). La construcción social de la realidad. Buenos Aires: Amorrortu editores.

Castoriadis, C. (1988). Poder, política y autonomía. Revue de Métaphysique et de la Morale.

Castoriadis, C. (1998). La cuestión de la autonomía social e individual. Contrapoder. COMPLETAR DATOS.

Castoriadis, C. (2001). Figuras de lo pensable. Las encrucijadas del Laberinto VI. México: FCE. FALTA CIUDAD

Cook T. y Reichardt, C. (1986). Métodos cualitativos y cuantitativos en investigación educativa. Madrid: Morata.

Cubides, J. (2012). Sujeto, política y movilizaciones sociales por la educación. Saarbrücken, Alemania: Editorial Académica 
Española. Marca de LAP LAMBERT Academic Publishing $\mathrm{GmbH} \&$ Co. KG.

Cubides, J. \& Mora, A. F. (Compiladores). (2009). Economía política de la educación: el caso de Bogotá. Grupo Interdisciplinario de Estudios Políticos y Sociales THESEUS. Bogotá: Universidad Nacional de Colombia.

Foucault, M. (1980). El orden del discurso. Barcelona: Tusquets Editores.

Foucault, M. (1991). El sujeto y el poder. Bogotá: Carpe Diem.

Foucault, M. (1992). Genealogía del racismo. Madrid: Ediciones de la Piqueta.

Gantiva, J. (2003). La pospolítica de la globalización o el atajo del multiculturalismo. En Estrada, J. Dominación, crisis y resistencias en el nuevo orden capitalista. Bogotá: Universidad Nacional de Colombia.

Guattari, F. (1996). Acerca de la producción de subjetividad. En Caosmosis. Buenos Aires: Ediciones Manantial.

Lechner, N. (1986). La conflictiva y nunca acabada construcción del orden deseado. Madrid: Siglo XXI Editores.

Martínez, Boom A. (2004). De la escuela expansiva a la escuela competitiva. Dos modos de modernización en América Latina. Barcelona: Anthropos.

Martínez, M. C. (2005). La figura del maestro como sujeto político. El lugar de los colectivos y redes pedagógicas en su agenciamiento. Revista Nodos y Nudos, 19.

Martínez, M. C. (2008) Redes pedagógicas y constitución del maestro como sujeto político. Bogotá: Magisterio.

Martínez, M. C. (2011). Cartografía de las movilizaciones por la educación en Colombia 19982007. Bogotá: Universidad Pedagógica Nacional y Editorial Magisterio.

Mead, G. (1982). Espíritu, persona y sociedad. Argentina: Paidós.

Mead, M. (1997). Cultura y compromiso. Estudio sobre la ruptura generacional. Barcelona: Editorial Gedisa.

Morin, E. (2001). La noción de sujeto. En La cabeza bien puesta. Repensar la reforma, reformar el pensamiento (pp. 129-140). Buenos Aires: Nueva Visión.

Múnera, L. (1994). Las dimensiones del Estado. En Constitución Política y reorganización del Estado. Bogotá: Universidad Nacional de Colombia.

Negri, A. (1994). Poder constituyente: el concepto de una crisis. En Negri, A. Poder constituyente. Ensayo sobre las alternativas de la modernidad. Madrid: Libertarias/Prodhufi.

Negri, A., \& Hardt, M. (2004a). Imperio. Buenos Aires: Paidós.

Negri, A., \& Hardt, M. (2004b). Multitud. Bogotá: Debate.

Reguillo, R. (2003). Ciudadanías juveniles en América Latina. Última Década, 19. 
Sztulwark, D. \& Duschatzky, S. (2005). ¿Qué puede una escuela? Notas preliminares sobre una investigación en curso. En: Frigerio, G. y Diker, G. Educar: ese acto político. Buenos Aires: Del Estante Editorial.

Zemelman, H. (1997). Subjetividad: umbrales del pensamiento social. Rubí (Barcelona): Anthropos. México: Centro Regional de Investigaciones Multidisciplinarias (Unam). 